\title{
PERAN GURU PAI DALAM MENINGKATKAN MOTIVASI BELAJAR SISWA MATA PELAJARAN PAI
}

\author{
Alif Achadah 1)* \\ Eka Desi Mulyati 2) \\ 1, 2 Universitas Islam Raden Rahmat Malang \\ *E-mail: achadahalif@gmail.co.id
}

\begin{abstract}
Education is very important in the development of a nation. With education the nation can become more advanced with the presence of a younger generation who is able to answer the challenges of the times. But in education it is not only aimed at increasing one's knowledge, but education also aims to make someone's behavior and morals better. So that in the application of learning in schools, the role of Islamic Education teachers is very important in to increase student motivation. In this study, taking the problem of "The Role of Islamic Education Teachers in Increasing Student Motivation in Islamic Education Subjects in SMP PGRI Kromengan Malang Regency" which is based on the phenomenon of PAI teachers who have a role in building student motivation. The research focus includes: 1) How is the student's learning motivation in Islamic Education learning? 2) What is the role of Islamic Education teachers in increasing student learning motivation in Islamic Education subjects at SMP PGRI Kromengan? 3) What are the obstacles and solutions of Islamic Education teachers in increasing learning motivation students in the PAI subject at SMP PGRI Kromengan?
\end{abstract}

Keywords: Islamic Education Teacher, Motivation to Learn

\begin{abstract}
Abstrak
Pendidikan merupakan hal yang sangat penting dalam perkembangan suatu bangsa. Dengan pendidikan pula bangsa dapat menjadi lebih maju dengan adanya generasi muda yang mampu menjawab tantangan perkembangan zaman. Tetapi dalam pendidikan bukan hanya bertujuan untuk meningkatkan pengetahuan seseorang tetapi pendidikan juga bertujuan untuk menjadikan perilaku dan akhlak seseorang menjadi lebih baik. Sehingga dalam penerapan pembelajaran disekolah, peran guru PAI sangatlah penting dalam upaya meningkatkan motivasi belajar siswa. Dalam penelitian ini mengambil permasalahan tentang "Peran Guru PAI Dalam Meningkatkan Motivasi Belajar Siswa Pada Mata Pelajaran PAI di SMP PGRI Kromengan Kabupaten Malang" yang hal tersebut dilatar belakangi karena adanya fenomena dari guru PAI yang mempunyai andil dalam membangun motivasi peserta didik. Adapun fokus penelitian meliputi : 1) Bagaimana motivasi belajar siswa dalam pembelajaran PAI?, 2) Bagaimana peran guru PAI dalam meningkatkan motivasi belajar siswa pada mata pelajaran PAI di SMP PGRI Kromengan?, 3) Apa saja kendala dan solusi guru PAI dalam meningkatkan motivasi belajar siswa pada mata pelajaran PAI di SMP PGRI Kromengan?
\end{abstract}

Kata Kunci: Guru PAI, Motivasi belajar

\section{PENDAHULUAN}

Persoalan pengajaran merupakan salah satu pembahasan yang dinilai penting serta perlu diperhatikan terkait aspek-aspek yang memengaruhinya. Diantara aspek yang krusial dalam pengajaran yaitu pengajar. Fungsi serta kewajiban pengajar dirasa sangat berat selain kewajibannya untuk mentransfer ilmu pengetahuan. Menjadi 
pengajar tidaklah kegiatan yang mudah, hanya bermodal pengetahuan pembelajaran dan menyampaikannya terhadap murid dirasa sudah sempurna. Kegiatan tersebuat tidak bisa di kategorikan termasuk pengajar yang profesional, kekhususan intelegensi, dedikasi terhadap profesinya, memelihara kode etik pengajar, dan masih banyak hal lain yang perlu di kuasai oleh guru. (Kompri, 2015).

Tiap individu tentulah sudah merasakan kegiatan pendidikan. Sebagian besar individu dalam melakukan proses pendidikan sebenarnya ada beberapa yang terlewati. Kegiatan tersebut timbul karena seorang individu menilai pendidikan tersebut sebagai hal yang harus dilakukan dan ditempuh, tetapi tidak sebagai kebutuhan dan puncaknya proses pendidikan sebagai kebiasaan (habit forming) yang sulit untuk ditinggalkan.

Istilah pendidikan menurut Kamus Besar Bahasa Indonesia (KBBI) berasal dari kata dasar "didik" (mendidik). Prof.Brodjonegoro mendefinisikan pendidikan adalah sebuah kebutuhan atas perkembangan individu sejak bayi hingga mecapai usia kematangan secara jasmani dan rohani sehingga bisa melaksanakan kewajibannya secara mandiri. (Nanang Purwanto, 2014).

Definisi Pendidikan adalah sebuah pengetahun atau mata pelajaran yang terstruktur dari beberapa hakikat dan cara pembelajaran, terstruktur dengan teratur (beraturan) sehingga bisa diterapkan dalam proses pengajaran didalam kelas sehingga dapat mencapai tujuan pembelajaran di lembaga pendidikan.

Lain halnya dengan Ki Hajar Dewantoro, beliau menyebutkan bahwa pengajaran adalah usaha dalam meningkatkan pertumbuhan akhlak serta etika, intelegensi, serta fisik peserta didik. Inti dari pengertian diatas yaitu agar pengajar bisa meningkatkan profesionalitas kerja serta meningkatkan integritas kehidupan, adalah keadaan peserta didik seimbang dengan perkembangan zaman. (Nanang Purwanto, 2014)

Definisi di atas juga sesuai dengan apa yang disampaikan oleh al-Ghazali, bahwa pendidikan tidaklah hanya meningkatkan aspek intelektualitas atau kognitif semata, melainkan juga aspek afektif (sikap), dan psikomotorik (perbuatan). Dengan ditujukan demi meningkatkan nilai spiritualitas manusia itu sendiri

Tercantum pada UU RI No. 20 dijelaskan tentang pengajaran adalah cara, upaya, serta ikhtiar yang terorganisir sebagai upaya menciptakan keadaan mencari ilmu sehingga murid dapat berperan aktif menggali kemampuan pribadi sehingga 
mempunyai kemampuan agama, karakter, intelektual, perilaku baik, dan mempunyai kemampuan dan keahlian yang dibutuhkan oleh lingkungan sosial.

Stimulan atau dorongan yaitu muncul dari dalam diri individu yang terjadi dengan sadar atau tidak sadar dalam upaya melaksanakan kegiatan dengan tujuan tertentu. (Kompri, 2015). Dorongan bisa juga timbul secara intern dari individu yang hal tersebut bisa dipastikan dengan kegiatan. Terkait dengan kegiatan pengajaran, adapun kewajiban yang signifikan yaitu melaksanakan upaya serta membuat keadaan yang membimbing murid dalam melaksanakan rutinitas melafalkan pelajaran dengan maksimal. Pengajar seyognyanya mencontohkan perilaku agar meragsang murid agar tangkas serta cakap dalam proses pembelajaran.

Menurut Kellough, menyebutkan bahwa proses pengajaran, kewajiban tutor yang signifikan adalah upaya memotivasi murid dalam menumbuhkan animo murid dalam menuntut ilmu. (Kompri, 2015).

Untuk menjalankan tugas diatas, pengajar harus faham serta mengerti sehingga pengajar dapat mentranasfer ilmu pengetahuan dan keahlian kepada murid, sehingga dapat menjadi daya tarik tersendiri, bernilai, dalam keadaan intrinsic menstimulus, mengajak untuk berbuat baik.

McCarty dan Siccone mengungkapkan tentang seberapa tinggi seorang pengajar mengetahui bakat muridnya, mengetahui ketrampilan muridnya, maka hal tersebut menunjukkan bertambahnya pengetahuan serta keefektifan pengajaran yang disampaikan kepada murid. (Kompri, 2015)

Motivasi serta pengajaran adalah 2 aspek yang memberikan dampak secara signifikan. Murid dapat bersemangat menimba ilmu apabila murid tersebut mempunyai keingian yang kuat untuk menimba ilmu dan mendapatkan pengetahuan. Thorndike, mendefinisikan bahwa belajar adalah sebuah prosedur atas adanya hubungan dari rangsangan (bisa berupa konsentrasi, emosi, kegiatan) dengan tanggapan. Definisi tersebut hampir sama dengan argumentasi Good dan Brophy, bahwa pengajaran adalah prosedur yang dilaksanakan oleh individu untuk mendapatkan ilmu pengetahuan seingga dapat merubah perilaku yang menajdi wujud pengalaman menimba ilmu.(Kompri, 2015). 
46 | Alif Achadah \& Eka Desi Mulyati

\section{METODE}

Sumber data adalah subjek darimana fakta didapatkan. (Suharsimi Arikunto, 1998). Fakta atau bahan yang didapat seharusnya didapat dari fakta yang benar sehingga tidak akan menimbulkan data atau fakta yang tidak berarti atau tidak signifikan dengan masalah yang diteliti. Adapun dalam data primer yaitu data pokok atau inti yang akan didapat dengan interview, atau observasi kepada pihak-pihak yang memang dibutuhkan. Data sekunder yaitu data riset yang didapat dengan cara instrumen seperti buku, catatan, arsip umum atau arsip yang hanya disimpan secara pribadi oleh obyek penelitian. (Suharsimi Arikunto, 1998). Metode pengumpulan secara kualitatif dikelompokkan kedalam dua jenis cara, yaitu teknik yang bersifat interaktif dan non interaktif. Metode interaktif sendiri meliputi interview dan observasi. Sedangkan metode non interaktif meliputi observasi tidak berperan serta.

\section{HASIL DAN PEMBAHASAN}

Telah diketahui bahwa dalam kegiatan pembelajaran adanya stimulasi dianggap sangat signifikan keberadaannya dan siswa pun sangat membutuhkan motivasi, siswa yang kurang semangat dalam menimba ilmu pengetahuan maka menjadi hal yang mustahil menjalankan kegiatan tersebut dengan baik dan maksimal, peristiwa ini yang terjadi pada siswa SMP PGRI 01 Kromengan.

Terkait dengan produk riset yaitu ada sebagian siswa SMP PGRI 01 Kromengan ketika mempelajari pendidikan agama islam masih memiliki motivasi yang kurang tetapi dengan usaha yang di lakukan oleh pengajar PAI untuk memajukan serta mengembangkan keinginan dan semangat menimba ilmu murid yang berakibat bahwa motivasi belajar siswa pun mulai tumbuh meskipun tidak signifikan, seorang pendidik harus dapat menimbulkan motivasi belajar.

Adapun tentang efek yang dihasilkan dari observasi yang dilaksanakan panelis menemukan kurangnya motivasi dalam menimba ilmu murid terkait dengan kegiatan belajar mengajar mata pelajaran PAI. Kegiatan tersebut bisa di lihat dari cara murid di sekolah ada yang terlambat karena bangun kesiangan, mengganggu temannya dll. Juga kesiapan siswa dalam pembelajaran masih kurang ada yang tidak membawa alat tulis, ada yang bukunya tertinggal sehingga disana terlihat usaha guru PAI dalam mewujudkan keinginan serta semangat menimba ilmu murid di SMP PGRI 01 
Kromengan, salah satunya adalah adanya arahan, pengajaran, menimbulkan keadaan yang menyenangkan serta adanya evaluasi pada setiap akhir pembelajaran.

Karena sangat pentingnya motivasi dalam belajar maka sangat di butuhkan campur tangan pengajar dalam usaha mewujudkan semangat menimba ilmu murid. Pada umumnya semua guru mengharapkan tercapainya tujuan pendidikan secara maksimal dengan di tandai dengan keberhasilan peserta didik dalam memahami ilmu pengetahuan yang di ajarkan. Maka setiap siswa harus lebih semangat dan bergairah dalam belajar.

Adapun peran guru dalam meningkatkan motivasi belajar siswa melalui proses:

1. Menyampaikan pengajaran

2. Mewujudkan serta melaksanakan keadaan pembelajaran yang menyenangkan dan sehat

3. Memberikan evaluasi

Dari ketiga peran guru di atas dapat diuraikan:

1. Memberi bimbingan

Seorang guru harus berusaha memberikan bimbingan dan arahan kepada siswa agara dapat meningkatkan kualitas belajar. Guru juga bisa memberikan tips tentang cara belajar yang efektif juga menyenangkan agar apa yang di harapkan tercapai.

2. Mewujudkan keadaan yang sehat serta menarik

Guru harus mampu mencptakan keadaan tempat yang menarik sehingga memungkin kan siswa dapat mengikuti pelajaran dengan tenang. Adapun peran yang dilaksanakan oleh pengajar PAI dalam menata lingkungan yang kondusif adalah menjadikan kelas bersih nyaman dan rapi. Guru dapat memberikan sanjungan kepada murid yang sudah menyelesaikan exam atau pekerjaan rumah (PR) dengan nilai tertinggi, pujian yang dilakukan dapat berupa memegang pundak siswa dan juga dapat dalam bentuk penguatan, misalnya "jawabanmu tepat sekali", "hasil kerjamu bagus" pujian sangat di perlukan serta dirasa efektif sebagai upaya memotivasi keinginan belajar yang sesungguhnya. Dengan adanya stimulus dari faktor eksternal, contohnya dalam meperoleh nilai yang baik, murid sewajarnya akan mengupayakan menjadi lebih semangat karena dorongannya juga lebih tinggi. 
3. Memberi penilaian

Nilai yang dimaksud yaitu lambang atau tanda dari hasil proses belajar mengajar. Pada umumnya murid yang menimba ilmu dengan alasan ingin mendapatkan nilai maksimal. Sehingga yang di kejar kadang hanya nilai-nilai ulangan dan nilai raport. Angka yang maksimal merupakan alat stimulus yang memadai dapat menimbulkan motivasi terhadap murid sebagai upaya menambah hasil belajarnya. Adapun hambatan pengajar PAI untuk meningkatkan motivasi belajar murid:

1. Kendala yang datang dari siswa

a. Minat: yaitu stimulus yang menimbulkan serta mengakibatkan berimbasnya perhatian murid terhadap obyek yang lebih khusus misalnya mata pelajaran. Siswa yang memiliki hasrat terhadap sesuatu lebih cenderung untuk memberika perhatiannya yang sangat spesifik kepada hal yang dihasratkan begitu juga sebalikanya.

b. Perbuatan atau perilaku: pada dasarnya pada kegiatan menimba ilmu, perilaku seseorang bisa mempengaruhi metode menimba ilmunya. Perlaku murid pada saat menimba ilmu bisa di pengaruhi oleh rasa bahagia atai tidak bahagia kepada guru, bidang studi atau keadaan sekitar.

c. Talenta: yaitu kekuatan yang tersembunyi pada individu sebagai cara dalam menggapai prestasi atau cita-cita. Jika bahan pelajaran yang di pelajari oleh murid itu senada atau seiring dengan talentanya pasti dia ekstra giat dalam beelajarnya begitu pula sebaliknya.

d. Famili/wali murid dalam meningkatkan motivasi belajar siswa. Daerah atau kawasan dirasa membawa dampak yang signifikan dalam mempengaruhi proses menimba ilmu. Konflik yang ada di keluarga, konflik ayah dan ibu, yang hal tersebut bisa membawa pengaruh negatif pada proses belajar murid.

e. Lingkungan sosial: keadaan masyarakat kawasan rumah murid juga sangat membawa dampak pada proses belajar muri. Kawasan yang kotor, banyaknya anak yang tidak bersekolah, banyak nya pengangguran, bisa berakibat mempengaruhi kegiatan menimba ilmu murid karena disini murid akan mengalami kemunduran dalam menemukan patner untuk belajar, diskusi dan bertukar peralatan atau buku yang belum di milikinya. 
f. Kendala pada kawasan lembaga pendidikan: kawasan lembaga pendidikan, contohnya pengajar, TU, dan teman satu kelas yang kesemuanya bisa mempengaruhi proses menimba ilmu murid.

Adapun solusi yang diperbuat kepala sekolah dan guru PAI sebagai upaya mewujudkan motivasi belajar murid di SMP PGRI 01 Kromengan adalah:

a. Jalan keluar guru PAI untuk meningkatkan dorongan belajar murid yang datang dari diri siswa:

1) Melakukan strategi personal : yang strategi tersebut bahwa guru PAI menjadi lebih mudah mengidentifikasi problematika yang di hadapi oleh siswanya.

2) Menumbuhkan animo serta hasrat murid : hal yang bisa dilakukan untuk menumbuhkan animo belajar murid yaitu cara memberikan apresiasi kepadanya. Memberikan apresiasi kepada siswa sama dengan memberi penguatan kepada siswa untuk melakukan tindakan yang positif. Tujuan memberi penguatan kepada murid supaya animo belajar murid meningkat.

b. Jalan keluar guru PAI dalam meningkatkan motivasi menimba ilmu siswa yang datang dari luar diri siswa:

1) Mengikut sertakan orangtua siswa dalam rapat sekolah

2) Menyalurkan berita atau penjelasan kepada wali murid tentang perkembangan anaknya di sekolah

c. Jalan keluar guru PAI dalam meningkatkan motivasi belajar siswa yang datang dari lingkungan masyarakat:

1) Memberi arahan kepada siswa untuk menjaga pergaulannya

2) Pihak sekolah dan guru bekerjasama untuk mengawasi anak didiknya di luar sekolah

d. Jalan keluar guru PAI dalam meningkatkan motivasi belajar siswa yang datang dari lingkungan sekolah:

1) Memberikan tugas kepada guru pengganti bagi guru mata pelajaran yang hadir

2) Pengajar pendidikan agama islam berkoordinasi dengan pegawai perpustakaan tentang buku yag kurang dan pengadaan buku baru

3) Mengadakan les pendidikan agama islam 


\section{SIMPULAN}

Keinginan atau dorongan belajar murid pada pelajaran PAI di SMP PGRI 01 Kromengan Kecamatan Kromengan Kabupaten Malang masih tergolong kurang, dapat dilihat dari sikap siswa saat proses belajar mengajar di kelas salah satunya masih ada siswa yang tidak serius dalam menerima pelajaran, dan ada yang ribut dikelas, mengganggu teman dan bolos. Namun dengan upaya yang dilaksanakan oleh pengajar PAI dalam mewujudkan kondisi yang aman, sehat, menarik, serta melakukan evaluasi dan bimbingan dapat meningkatkan motivasi belajar siswa.

1. Peran pengajar PAI dalam meningkatkan motivasi menimba ilmu murid dalam pelajaran PAI di SMP PGRI 01 Kromengan Kecamatan Kromengan Kabupaten Malang yaitu dengan : (a) memberi bimbingan. (b) mewujudkan serta melaksanakan kondisi kelas yang sehat, aman, dan menarik (c) melakukan evaluasi.

2. Kesulitan serta jalan keluar guru PAI dalam meningkatkan motivasi belajar murid pada pembelajaran pendidikan agama islam di SMP PGRI 01 Kromengan Kecamatan Kromengan Kabupaten Malang di sebabkan oleh 2 faktor yaitu 1) Kendala yang datang dari diri siswa : apabila motivasi belajar tidak terdapat pada diri siswa sendiri maka keinginan untuk belajar akan sulit di dapatkan. Karena tidak adanya minat belajar, maka siswa akan merasa malas belajar, tidak menghiraukan pelajaraan, mengganggu teman di kelas, bolos dan datang terlambat dansebagainya. 2) Kendala yang datang dari luar diri siswa: (a.) Kendala datang dari keluarga (b.) Kendala datang dari lingkungan massyarakat (c) Kendala datang dari lingkungan sekolah

\section{DAFTAR PUSTAKA}

Ali, Mohammad. 1987, Penelitian Kependidikan Prosedur dan strategi. Bandung: Angkasa.

Arikunto, Suharsimi. 2006. Prosedur Penelitian Suatu Pendekatan Praktek. Jakarta: Rineka Cipta.

Arikunto, Suharsimi. 1998. Pengantar Penelitian Suatu Pendekatan Praktek, Jakarta: Rineka Cipta.

Ghoni, M.junaedi. 2010. Metodologi Penelitian Kualitatif. Jakarta: Arrus Media.

Moleong, Lexy J. 2016. Metodologi Penelitian Kualitatif. Bandung: Remaja Rosda Karya. 
Kompri. 2015. Motivasi Pembelajaran. Bandung: PT Remaja Rosdakarya.

Muflihin, A., \& Madrah, M. Y. (2019). Implementation of Al-Ghazali's Islamic Education Philosophy in the Modern Era. Al-Fikri: Jurnal Studi Dan Penelitian Pendidikan Islam,2, 13-27. http://jurnal.unissula.ac.id/index.php/fikri/article/view/4012 Purwanto, Nanang. 2014. Pengantar Pendidikan. Yogyakarta: Graha Ilmu. Sugiono. 2015. Metode Penelitian Kuantitaif, Kualitatif. Bandung: Alfabeta. S.Margono. 2000. Metodologi Penelitian Pendidikan. Jakarta: PT. Rineka Cipta. 